\title{
Hom-Kularb-Dang Rice Bran Extract for the Prevention of UVB-Damage Against Human Skin Fibroblast
}

\author{
Swanya Yakaew ${ }^{1}$, Preeyawass Phimnuan ${ }^{1}$, Khomsan Tiensomjitr ${ }^{1}$, \\ Wongnapa Nakyai ${ }^{2}$, Nitra Nuengchamnong ${ }^{3}$, Gareth Ross $^{4}$, \\ Malyn Ungsurungsei ${ }^{5^{*}}$, and JarupaViyoch ${ }^{1^{*}}$
}

${ }^{1}$ Department of Pharmaceutical Technology, Faculty of Pharmaceutical Sciences and Center of Excellence for Innovation in Chemistry, Naresuan University, Phitsanulok 65000, Thailand

${ }^{2}$ Department of Chemistry, Faculty of Science, Ramkhamhaeng University, Bangkok 10240, Thailand

${ }^{3}$ Science Laboratory Center, Faculty of Science, Naresuan University, Phitsanulok 65000, Thailand

${ }^{4}$ Department of Chemistry, Faculty of Science, Naresuan University, Phitsanulok 65000, Thailand

${ }^{5}$ Research \& Development Division, $S \& J$ International Enterprises Public Company Limited, Bangkok 10120, Thailand.

*Corresponding author. E-mail: jarupav@nu.ac.th, malyn@snjinter.com https://doi.org/10.12982/CMUJNS.2020.0003

Received: March 11, 2019

Revised: May 2, 2019

Accepted: May 10, 2019

\section{ABSTRACT}

In this study, we investigated the protective effect of hydroglycolic crude extract of Thai red Hom-Kularb-Drice (HKD) rice bran on UVBinduced photoaging of human skin fibroblast. The HKD rice bran extract showed scavenging capacity with an $E C_{50}$ of $4.37 \pm 0.34 \mathrm{mg} / \mathrm{mL}$ testing using a DPPH radical scavenging assay. The structural identification of proanthocyanidins compounds was performed by Liquid chromatographyelectrospray ionization-quadrupole-time-of flight mass spectrometry (LCESI-Q-TOF-MS) in the hydroglycolic HKD extract. These compounds were cyanidin B2 type and (epi) catechin. The extract showed a no cytotoxic response was showed in human skin fibroblast. Furthermore, the HKD extract $(20 \mu \mathrm{g} / \mathrm{mL})$ exhibited a protective effect in $U V B$ irradiated primary skin fibroblast, reducing MMP-1 (matrix metalloproteinases-1) expression and increasing production of type I procollagen. This data suggests that the 


\section{HKD rice bran extract has potential for use as a skin anti-aging agent in cosmetic products.}

Keywords: Hom-Kularb-Dang rice bran extract, UVB, Human skin fibroblast, MMP-1, Type I procollagen.

\section{INTRODUCTION}

Skin exposure to sunlight is known to cause damage usually referred to as photoaging. The part of the electromagnetic spectrum that causes the majority of this damage is in the ultraviolet range $(200-400 \mathrm{~nm})$ and section which is of most concern to skin health is between the wavelengths of 280-315 nm or UVB. Chronic exposure to UVB leads to the breakdown of collagen, which is the main component of the skin extracellular matrix (ECM) and also reduces the synthesis of procollagen type I (Quan et al., 2004; Viyoch et al., 2012). Disarrangement of the collagen matrix in dermal tissue by matrix metalloproteinases (MMPs) results in UV irradiation- induced photoaging (Quan et al., 2009). The mechanism of UVB-induced collagen degradation is caused by the formation of various radical oxygen species (ROS) provoking the mitogen-activated protein (MAP) kinase pathway, which up-regulates activator protein 1 (AP-1). Activation of AP-1 induces the expression of MMPs in human skin fibroblasts (Chiang et al., 2012; Wen et al., 2012). These enzymes include MMP- 1 (interstitial collagenase- 1), MMP- 8 ( neutrophil collagenase, collagenase-2) and MMP- 13 (collagenase-3). MMP- 1 is the main primary mediator in enhanced damage of type I collagen during UV-induced photoaging (Choi et al., 2007; Dong et al., 2008). Therefore, it has been proposed that prevention of collagenase enzymes might be a strategy for precluding UVaccelerated skin aging by reverting the balance between synthesis and collagen degradation (Ahn et al., 2012; Itsarasook et al., 2014; Park et al., 2014).

Hom-Kularb-Dang (HKD), or Thai red rice is cultivated and consumed in the northern region of Thailand for more than a decade. Several studies have reported that they are many health benefiting components present in the bran part of the rice kernel. These components functions include; free radical scavenging, antioxidation potential (Chotimarkorn et al., 2008; Butsat and Siriamornpun, 2010), immunomodulatory activity and (Chen et al., 2010) and cancer and heart disease prevention (Kannan et al., 2010; Leardkamolkarn et al., 2010; Bhupathiraju and Tucker, 2011). The compounds found include sterols, oryzanol, tocopherols, tocotrienols and phenolics (Aguilar et al., 2007; Samad, 2015). One of the more important family of compounds present in HKD are proanthocyanidins, which are known as natural strong anti-oxidants that only can be found in red fruits and red rice (Gunaratne et al., 2013; Huang and Lai, 2016).

The work presented herein investigates the protective effect of hydroglycolic HKD rice bran crude extract on MMP- 1 and type I procollagen 
production when exposed to UVB-irradiated human skin fibroblast. To the authors knowledge, there is no previously evidence on the anti-oxidant activity, proanthocyanidin content, cytotoxicity and preventive effect of the HKD rice bran extract against UVB-damaged.

\section{MATERIALS AND METHODS}

\section{Chemicals and Materials}

2, 2-diphenyl-1-picrylhydrazyl was purchased from Sigma-Aldrich, Missouri, USA. Dispase, amphotericin B and fetal bovine serum (FBS) was purchased from Gibco, Auckland, New Zealand. Trypsin EDTA solution was purchased Gibco, Ontario, Canada. Penicillin-streptomycin solution $(10,000$ units $/ \mathrm{mL}$ penicillin and $10,000 \mu \mathrm{g} / \mathrm{mL}$ streptomycin) was purchased from Gibco, New York, USA. Sodium 3'-[1-(phenylamino)-carbonyl]-3, 4-tetrazolium]bis(4-methoxy-6-nitro) benzene-sulfonic acid hydrate (XTT) was purchased from Roche Diagnostics Corporation, Indiana, USA. Acetonitrile (LC-MS reagent) and water (LC-MS grade) were purchased from RCI Labscan Limited (Bangkok, Thailand). Formic acid (analytical grade) was purchased from JT Baker (Philipsburg, NJ, USA). Anylon syringe filter $0.45 \mu \mathrm{m}$ was bought from Lubitech Technologies Ltd. (Shanghai, China).

\section{Plant material}

Hom-Kularb-Dang, red rice was collected from Sukothai province, Thailand and kindly prepared by S\&J International Enterprises Public Co., Ltd., Bangkok, Thailand.

\section{Crude HKD extract preparation}

The rice bran of Hom-Kularb-Dang (HKD, PRE90 020-R36-PSL-8-3-143 ) was first harvested after that, the whole rice grains were dried. Then the rice bran was separated and extracted using the method described by Chulasiri et al. (2011). Briefly, bran rice was macerated in a 50\% hydroglycol solution at a ratio of 1:7 for 3 days. The macerate was filtered, and the filtrate was designated as the ready to use crude hydroglycolic extract of the rice bran.

\section{DPPH (2, 2-diphenyl-1-picrylhydrazyl) assay}

DPPH radical scavenging activity was determined using the method previously described (Itsarasook et al., 2014; Phetdee et al., 2014; Yakaew et al., 2016). Briefly, $1 \mathrm{ml}$ of $0.2 \mathrm{mM}$ DPPH solution (Sigma-Aldrich Chemic $\mathrm{GmbH}$, Steinheim, Germany) was mixed with $0.5 \mathrm{ml}$ of various concentrations of the sample of extract previously dissolved in methanol. The mixtures are kept at ambient temperature for $30 \mathrm{~min}$, prior to absorbance measurement at $515 \mathrm{~nm}$ 
using a UV-Vis spectrophotometer. L-Ascorbic acid (vitamin C) was used as the positive control and the radical scavenging activity was calculated as a percentage of DPPH decoloration using the following equation:

$$
\% \text { Radical scavenging activity }=\left[1-\left(\mathrm{A}_{\mathrm{S}} / \mathrm{A}_{\mathrm{B}}\right)\right] \times 100
$$

where, $A_{S}=$ absorbance of DPPH with the tested sample and $A_{B}=$ absorbance of DPPH without tested sample. $\mathrm{EC}_{50}$, the equivalent concentration to give the $50 \%$ effect, was determined by log- prohibit analysis using seven different concentrations of the tested samples. The study was run in triplicate.

\section{Identification of proanthocyanidins in HKD rice bran extracts by ESI-Q- TOF-MS}

Conditions for ESI-Q-TOF-MS were the same as in the previous study (Duangjai et al., 2016). A 6540 ultrahigh definition accurate mass Q-TOF (Agilent Technologies, Palo Alto, CA, USA) was converted into an Agilent 1260 infinity high performance liquid chromatography instrument (Agilent, Waldbonn, Germany) via an ESI interface. Analysis parameters were set using both negative and positive ion modes with spectra acquired over a mass range of $\mathrm{m} / \mathrm{z}$ 100-1,000 amu. The ESI-MS condition parameters were as follows: capillary voltage, $+3,500 \mathrm{~V}$; dry gas temperature, $350{ }^{\circ} \mathrm{C}$; dry gas flow, $10 \mathrm{~L} / \mathrm{min}$; nebulizer pressure, 30 psig; and spectra rate, $4 \mathrm{~Hz}$. Fragmentations were performed using auto MS/MS experiments with collision energies at $10 \mathrm{~V}, 20 \mathrm{~V}$, and $40 \mathrm{~V}$, with nitrogen used as the collision gas. Chromatographic separation was performed using a phenomenex Luna C-18(2) column $(5 \mu \mathrm{m}, 150 \times 4.6 \mathrm{~mm}$ internal diameter) (Phenomenex Inc., Torrance, CA, USA). The mobile phase consisted of $0.1 \%$ formic acid in water $\mathrm{v} / \mathrm{v}$ (Solvent $\mathrm{A}$ ) and $0.1 \%$ formic acid in acetonitrile $\mathrm{v} / \mathrm{v}$ (Solvent B). The linear gradient started from 10\% to $90 \%$ of Solvent B for 30 minutes. The injection volume was $5 \mu \mathrm{L}$ and the mobile phase flow rate was 0.5 $\mathrm{mL} / \mathrm{min}$. Peak identification was performed by comparing the mass spectra, and fragmentation patterns against reported data, and a library search of the MassHunter METLIN metabolite database (Agilent Technologies).

\section{Cytotoxicity of extract exposed to human skin fibroblasts}

Cell isolation and cultivation. Human skin samples were obtained from eyelid of women aged 50-60, after surgery. The procedure was approved by the ethical committee of Naresuan University (IRB No. 355/57).

The explant technique was used for dermal isolation. The dermal layer was washed with phosphate buffered saline (PBS) and antibiotics (penicillin/streptomycin). Then, the skin tissue samples were cut into 4-5 pieces 
( $2 \mathrm{~mm}$ square) and placed into $25 \mathrm{~cm}^{2}$ culture flasks and subsequently incubated in $5 \% \mathrm{CO}_{2}$ at $37{ }^{\circ} \mathrm{C}$. During this process the tissue adhered to the culture flask. A culture medium consisting of Dulbecco's Modified Eagle's Medium (DMEM, low glucose, Sigma-Aldrich) supplemented with 10\% Fetal bovine serum (FBS, Cultilab, Campinas, São Paulo, Brazil) and 1\% of stock penicillin/streptomycin solution (100 U/ml Penicillin and $100 \mu \mathrm{g} / \mathrm{ml}$ Streptomycin, Gibco ${ }^{\mathrm{TM}}$, Invitrogen, New York, USA), was added to each flask. After incubation for 3 weeks at $37^{\circ} \mathrm{C}$ with $5 \% \mathrm{CO}_{2}$, the fibroblast cells had migrated from the original explant site. After trypsinization, cells were seeded at $1 \times 10^{4}$ cells $/ \mathrm{cm}^{2}$ in $75 \mathrm{~cm}^{2}$ flasks using the same medium. Passage numbers 2 to 8 were used in this study.

Cell viability test. Cell viability was assessed using sodium $3^{\prime}$ - [( phenylamino)-carbonyl]-3,4,tetrazolium-bis (4-methoxy-6-notro) benzene-sulfonic acid hydrate (XTT, Boehringer Mannheim, Mannheim, Germany) assay (Inpanya et al., 2012; Phetdee et al., 2014; Yakaew et al., 2016). The cells were seeded at $1 \times 10^{4}$ cells $/ \mathrm{cm}^{2}$ into each well of 96 well plates. Cultured with $250 \mu 1$ of supplemented DMEM at $37{ }^{\circ} \mathrm{C}$ with $5 \% \mathrm{CO}_{2}$. After $24 \mathrm{~h}$, cells were treated with HKD extract $(0.625-20 \mu \mathrm{g} / \mathrm{mL})$ in serum free medium. After incubation for $24 \mathrm{~h}$, $200 \mu \mathrm{l}$ of serum free medium and $50 \mu \mathrm{l}$ of XTT solution were added. The cells were further incubated for $4 \mathrm{~h}$. The absorbance was measured on a microplate reader at $490 \mathrm{~nm}$, and the number of viable cells was calculated as the percentage of the optical density of the untreated group. The control group consisted of cells treated with 50\% hydroglycol in DMEM. The number of samples used in each group was 3 .

\section{Determination of preventive effects of the extract on UVB- induced alterations in human skin fibroblasts}

UVB irradiation. A fluorescent sun lamp (Toshiba FL8BLB, Japan) with an emission spectrum between 275-305 $\mathrm{nm}$, was used as the source of UVB radiation, placed $22 \mathrm{~cm}$ above the cell culture flasks. The UVB intensity used in this study was $128 \mathrm{~J} / \mathrm{cm}^{2}$. Preliminary data indicated that this selected intensity is a sublethal dose, which inactivates the fibroblasts to undergo proliferation (Yakaew, 2013). These UVB-irradiated cells could perform normal cellular functions when they were re-cultured.

Human skin fibroblasts at $2.0 \times 10^{6}$ cells in a $25 \mathrm{~cm}^{2}$ flask were maintained overnight in culture media. The cells were pretreated with $20 \mu \mathrm{g} / \mathrm{mL}$ HKD for $24 \mathrm{~h}$ and were then washed and covered by an $\sim 1 \mathrm{~mm}$ deep layer of PBS before exposing to UVB irradiation (extract + UVB group). Following the UVB irradiation, the PBS was replaced by a serum-free culture medium, and the cells were incubated for further $24 \mathrm{~h}$. At the end of the incubation period, the supernatant of the cultured fibroblasts was collected and stored at $-80^{\circ} \mathrm{C}$ until testing of type I procollagen and MMP- 1 analysis. The supernatants from the groups of non-UVB irradiated cells and UVB-irradiated cells without extract 
treatment were also collected. The number of samples used in each group was 3 . Moreover, the viability of the cells from each group was assessed.

Type I procollagen and MMP-1. ELISA kits were used to measure the levels of type 1 procollagen protein (Human Procollagen type I C-peptide (PIP) EIA Kit, Takara Bio Inc., Shiga, Japan) and MMP-1 (Ray Biotech, Inc. Georgia, USA) in cell-free supernatants. The assay was performed according to the manufacturer's instructions.

\section{Statistical analysis}

All values were expressed as means of each treatment group. Student's unpaired t-tests were used to compare between the two groups. $P<0.01$ was considered statistically significant.

\section{RESULTS}

\section{Anti-oxidant activity}

The HKD extract (0.001-50 mg/mL) showed a concentration-dependent reduction of DPPH activity and that the $\mathrm{EC}_{50}$ was $4.37 \pm 0.34$, compared to $0.01 \pm$ $0.0053 \mathrm{mg} / \mathrm{mL}$ for the vitamin $\mathrm{C}(0.0001-1 \mathrm{mg} / \mathrm{mL})$, a well-known anti-aging agent used in cosmetics as a positive control.

\section{Identification of proanthocyanidins in the HKD extract}

Based on different molecular masses of chemical constituent in the crude extract, proanthocyanidins can be separated with LC-ESI-QTOF-MS. The HKD total negative ion chromatograms presented (epi) catechin (Figure 1) and procyanidin B type (Figure 2). ESI-MS spectra showed a series of polyflavan-3ols for procyanidin type B2. In Figure 1, the [M-H]- ion at $\mathrm{m} / z$ 289.0713, proposes a molecular weight of 290 for (epi) catechin. This was confirmed by MS/MS data shown in Figure 3 as (epi) catechin gave similar values as found in the literature ( $\mathrm{Lv}$ et al., 2014). In addition, the [M-H]- ion at $\mathrm{m} / z$ 577.1346 suggested a molecular weight of 578 for the procyanidin dimer with a B2 type inter-flavanoid linkage (Figure 2) (Zhao et al., 2006; Lv et al., 2015). Amongst the ion products of MS/MS, the ion at $m / z 451.1104$ [M-H-126]- resulted from the elimination of a phloroglucinol molecule from the B-type dimer, ions at $\mathrm{m} / \mathrm{z}$ 407.0835 [M-H-170]- and $m / z$ 289.0751 [M-H-288]- were from the RDA fission of a B-type dimmer ( $\mathrm{Gu}$ et al., 2003; Lv et al., 2015). This was identified as procyanidin B2 according to the literature (Figure 4) (Gu et al., 2003; Lv et al., 2015). 


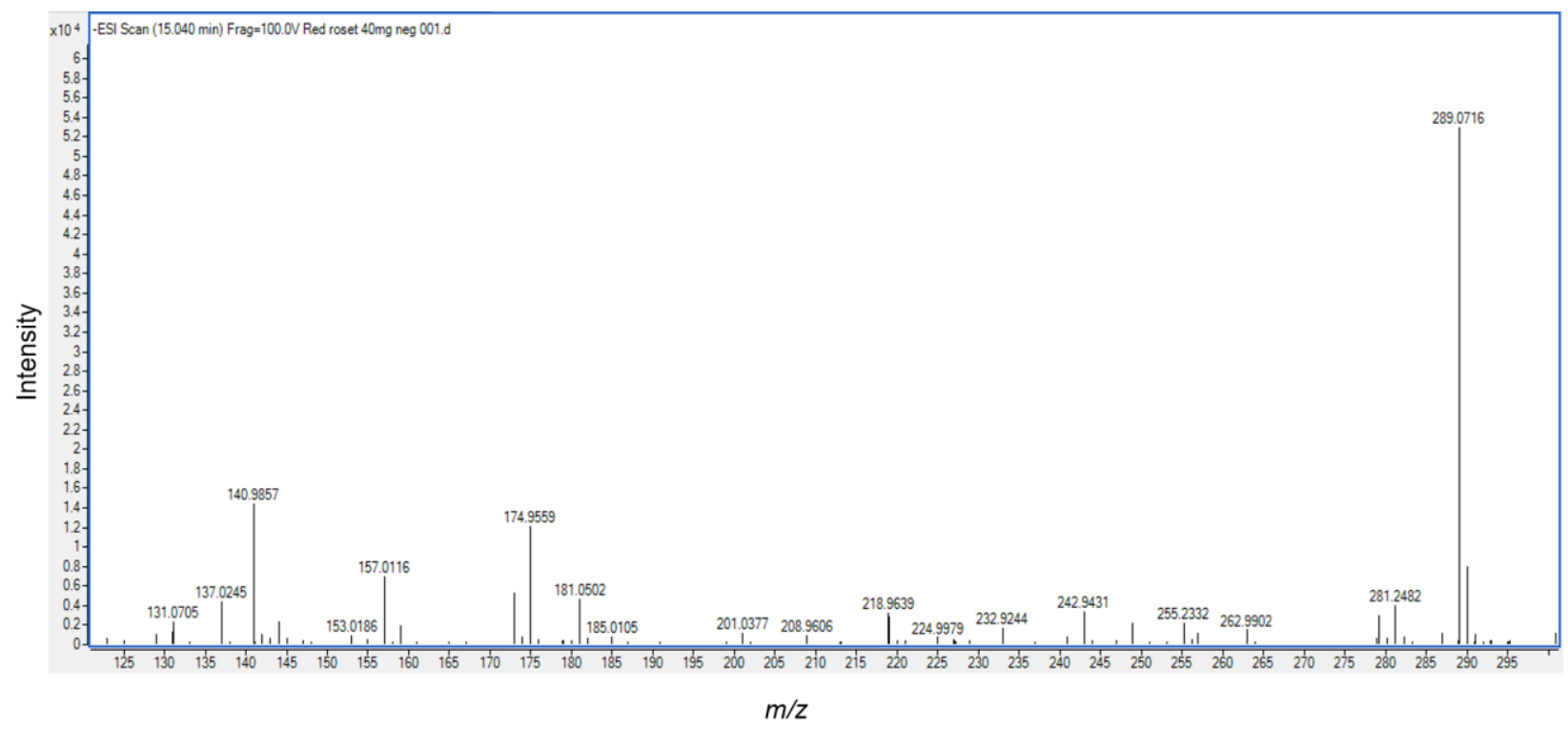

Figure 1. Electrospray Ionization Mass Analysis (ESI) of the HKD extract. The sample contained (epi)catechin (mw.289), was analyzed by ESI/MS.

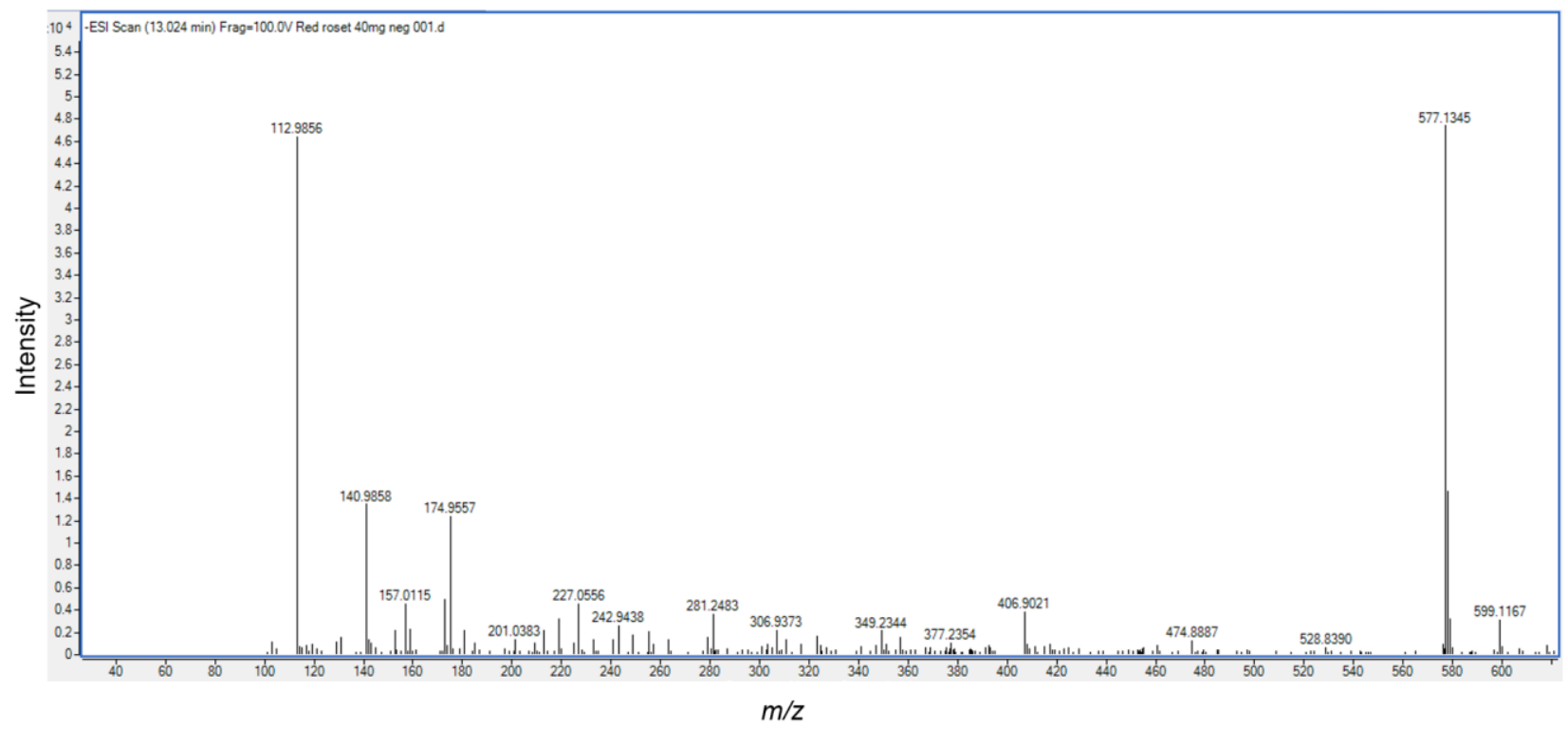

Figure 2. Electrospray Ionization Mass Analysis (ESI) of the HKD extract. The sample contained procyanidin B2 type (mw.577), was analyzed by ESI/MS. 


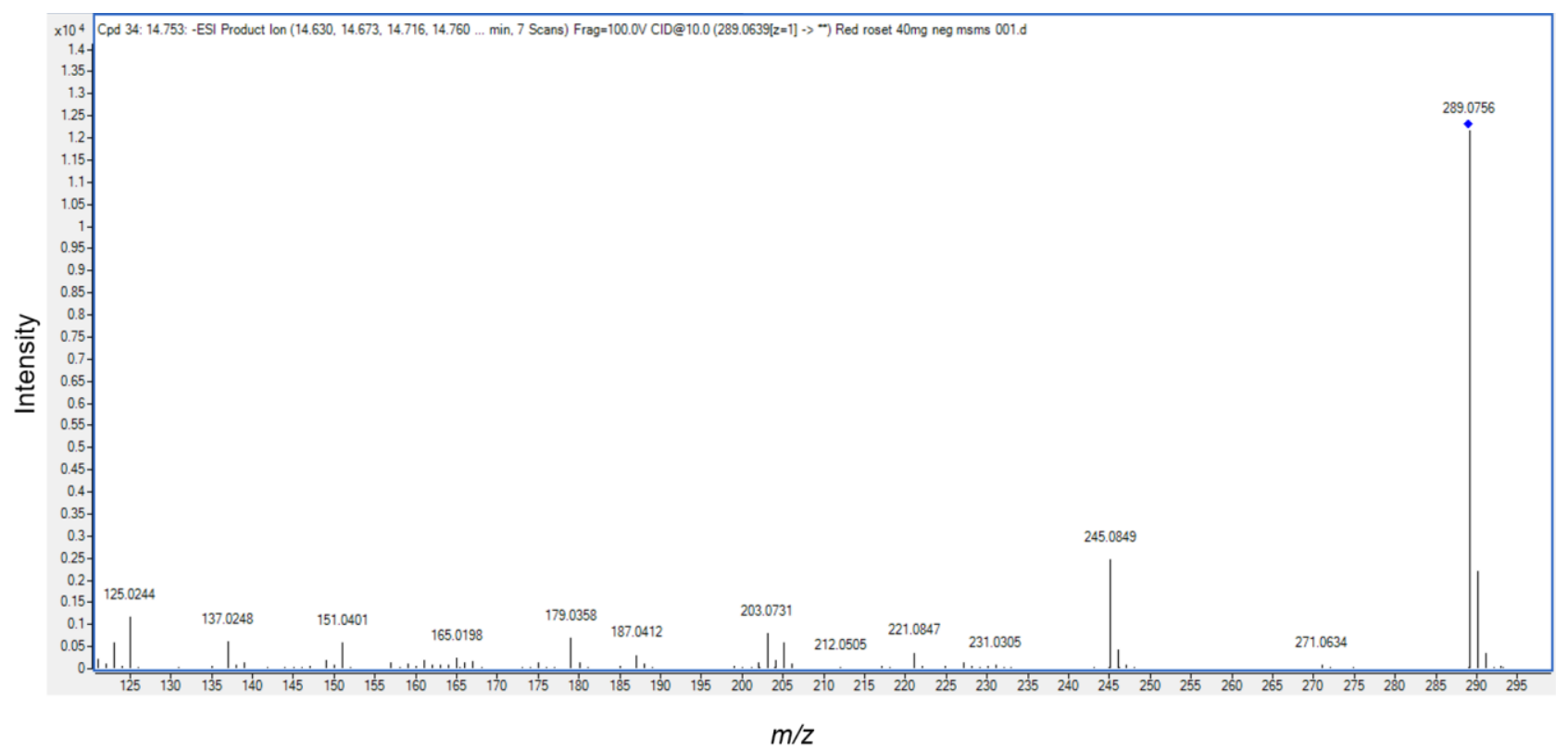

Figure 3. Electrospray Ionization Mass Analysis (ESI) of the HKD extract. The structure of (epi) catechin (mw.289) with major fragmentations and the relative abundance of the product detected by ESI/MS/MS.

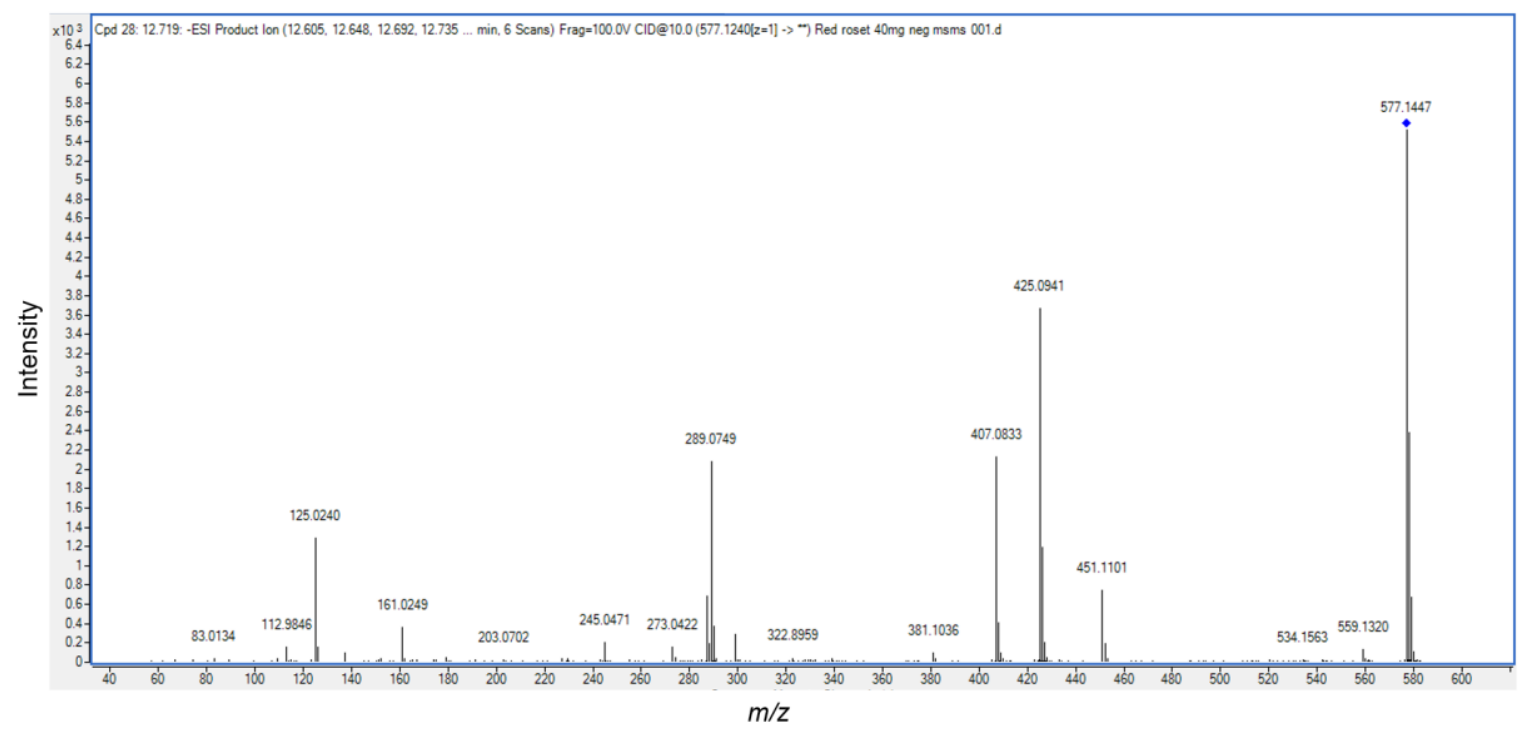

Figure 4. Electrospray Ionization Mass Analysis (ESI) of the HKD extract. The structure of procyanidin B2 type (mw.577) with major fragmentations and the relative abundance of product detected by ESI/MS/MS. 


\section{Cytotoxicity to human skin fibroblasts}

For different extract concentrations $(0.625-20 \mu \mathrm{g} / \mathrm{mL})$ and incubation time of $24 \mathrm{~h}$, the result showed the extracts had no significantly effect on the viability when exposed to human skin fibroblasts (Figure 5). Moreover, the treatment of the human skin with the highest concentration $20 \mu \mathrm{g} / \mathrm{mL}$ did not alter cell morphology (Figure 6B). Therefore, the extract at a concentration of $20 \mu \mathrm{g} / \mathrm{mL}$ was used for all subsequent experiments.

\section{Effect of the rice bran on type I procollagen and MMP-1 productions in UVB-irradiated human fibroblasts}

In this study, we found that UVB irradiation on fibroblasts suppressed type I procollagen production and, by contrast, enhanced MMP-1 expression. The level of type I procollagen in UVB-irradiated cells and non UVB-irradiated cells is shown in Figure 6A. At $24 \mathrm{~h}$ after UVB irradiation, the procollagen level of the UVB-irradiated group significantly decreased as compared to non-irradiated (control) group. The fibroblast pretreated with the HKD extract (pretreated group) before exposure to UVB irradiation exhibited markedly increased type I procollagen secretion compared to the UVB irradiation only $(P<0.01)$ or control group. In addition, the fibroblasts produced substantial amounts of MMP-1 after UVB irradiation for $24 \mathrm{~h}$ (Figure 6B) but UVB-induced MMP-1 expression was impeded in cells pretreated with the extract. 


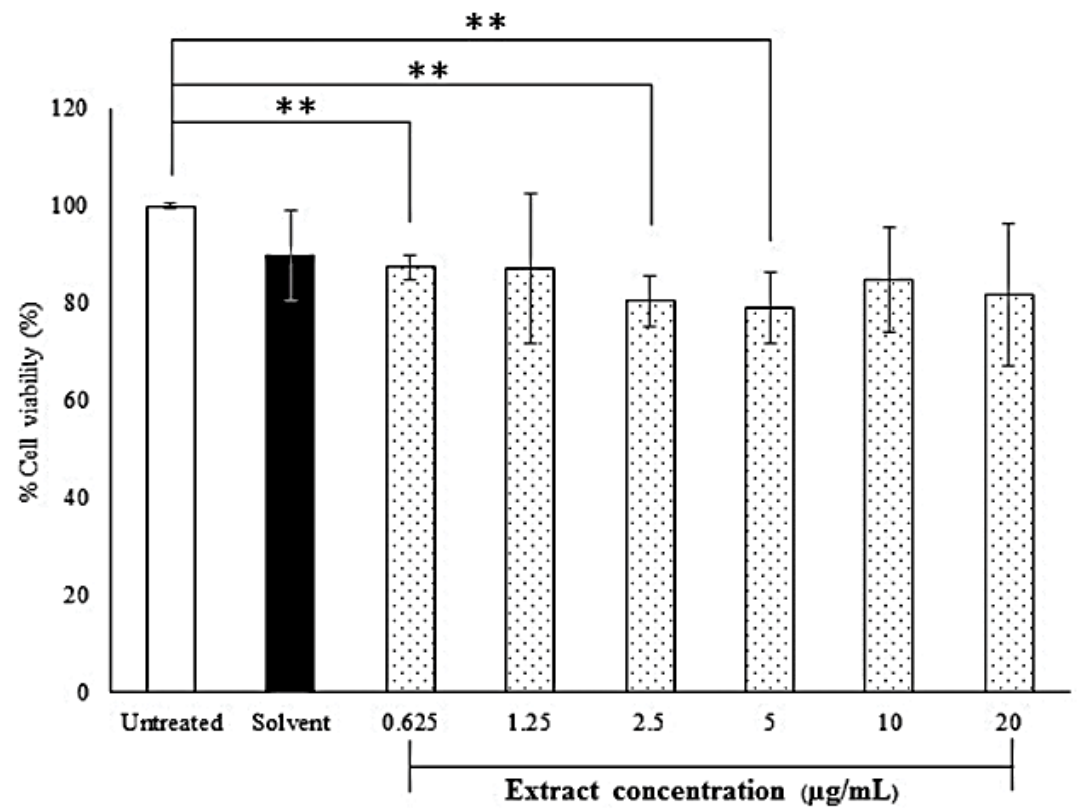

Figure 5. Effect of the HKD extract on viability of primary human skin fibroblasts. Untreated cells were control cell. Solvent was cells-treated with $50 \%$ hydroglycol at amount of $20 \mu \mathrm{g} / \mathrm{mL}$ (highest concentration of the extract treated with the cells) or the extract at concentrations in range of 0.625 to $20 \mu \mathrm{g} / \mathrm{mL}$ for $24 \mathrm{~h}$. Results are expressed as percentage of cell viability ( $\%$ ) as compared to untreated cells for which the optical density was adjusted to $100 \%$. Each bar represents mean $\pm \mathrm{SD}$ of $3 \mathrm{n}, * * P<0.01$, when compared between two groups (Student's $t$-test). 

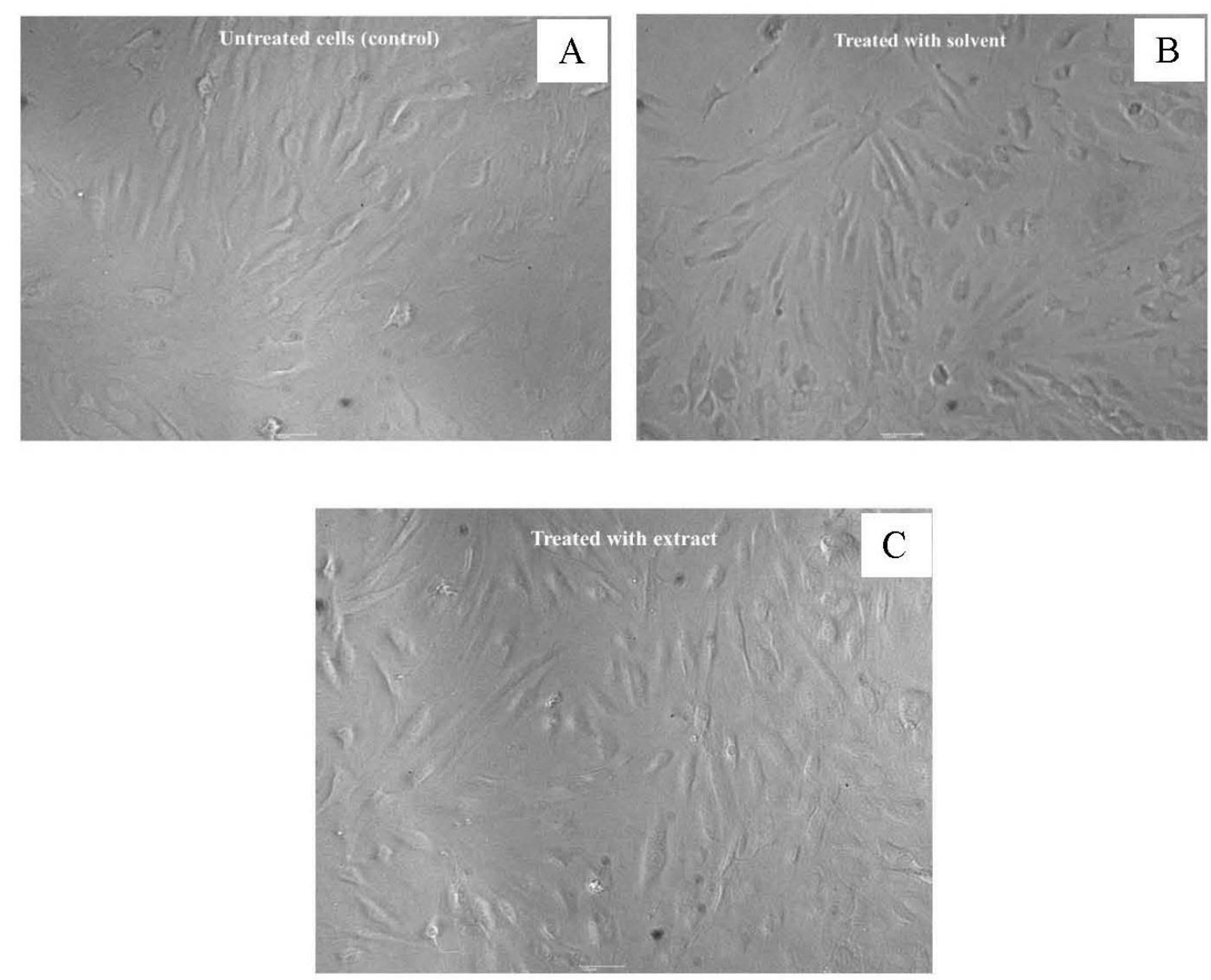

Figure 6. Morphology of primary human skin fibroblasts at magnification of 10x, untreated cells (control) (A), cell-treated with solvent (50\% hydroglycol) (B), and cell-treated with $20 \mu \mathrm{g} / \mathrm{mL}$ extract (C). 

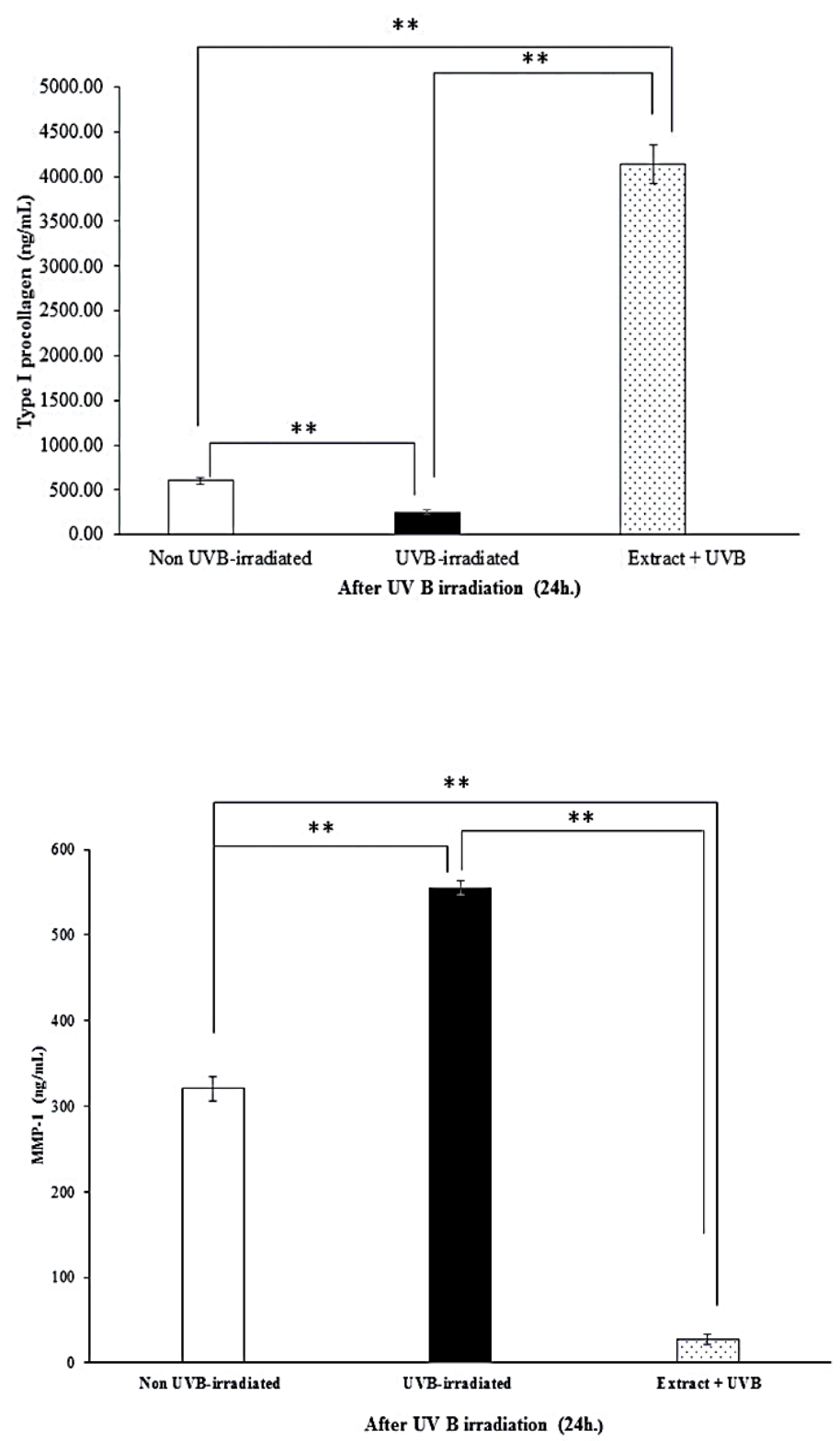

Figure 7. Effects of the extract $(20 \mu \mathrm{g} / \mathrm{mL})$ on type I procollagen (A) and MMP-1 (B) productions by UVB-irradiated human skin fibroblasts at $24 \mathrm{~h}$ after irradiation. Each bar represents mean \pm SD of $3 \mathrm{n}$. $* * P<0.01$, when compared between two groups (Student's $t$-test).

\section{DISCUSSION}

The HKD crude extract from Thai red rice bran contained proanthocyadinins that are composed of flavanol unit of (epi) catechin and the MS/MS spectra in the negative mode showed three main fragments at $\mathrm{m} / \mathrm{z} 451,407$ and 289, respectively. These were identified and named as procyanidin type B2. Procyanidins are a complex family of polyphenol polymers widespread in nature, 
which act as an anti-oxidants by neutralizing oxidizing free radicals, including superoxide and hydroxyl radicals (Torel et al., 1986; Ricardo et al., 1991; Bagchi et al., 1997). Our data are correlated with those previously reported on other red rice bran extracts ( $\mathrm{Gu}$ et al., 2003). Anti-oxidant activity of proanthocyanidin contained in hydroglycolic HKD rice bran has not been reported. In this present study, we found that the extract promoted a lower anti-oxidant activity than that of vitamin $\mathrm{C}$. The result may be due to from the slow reaction of the phenolics in the extract with DPPH compared to vitamin $\mathrm{C}$, which is a non-phenolic compound. Non-phenolic compounds such as vitamin C, present fast reactions with the DPPH radical (Sanchez et al., 1998).

In addition, exposure of the extract to human skin fibroblast showed no cytotoxic, with no alteration of the typical spindle-shape cell morphology. These enabled to use the highest concentration of the HKD crude extract for all experiments.

For UVB irradiation of fibroblasts affect biological pathways, such as MAP kinase resulting in up-regulation of MMPs. This up-regulation leads to the down-regulation of procollagen expression. MMP-mediated collagen breakdown is a major biochemical characteristic of photodamaged human skin (Fligie et al., 2003; Wang et al., 2007; Quan et al., 2009). UVB irradiation induces the secretion of various MMPs and concurrently provisionally suppresses type I collagen gene expression. These incidents can cause the impairment of the structural integrity of the dermis (Brennan et al., 2002; Varani et al., 2002). The extract was found to inhibit UV-induced MMP-1 production and UV-induced decrease of type I procollagen synthesis, probably due to the inhibition of UV-induced AP- 1 activity (Déziel et al., 2010; Limtrakul et al., 2016). Amid MMPs family, MMP1 induction has the greatest impact on collagen damage. In the current study, pretreatment with HKD extract reduced MMP-1 secretions. Moreover, the extract could enhance the level of extracellular type I procollagen. This could imply that the anti-oxidant effect of the rice bran extract inhibits UVB-induced ROS formation, which attenuates a provocation of the MAP kinase pathway. Another possibility is that the extract might improve the activities of the transcription factor corresponding to procollagen expressions. These hypotheses are based on the results from a previous study showing that phenolic compounds such as procyanidin, epicatechin can enhance transcription factors determining antioxidant reponse element ( $\mathrm{Lu}$ and Foo, 1999; Wittenauer et al., 2015). Enhancement of the permeation and improvement of the stability of procyanidin by devising appropriate formulations areneeded.

\section{CONCLUSION}

In conclusion, we demonstrated that pretreatment with hydroglycolic solution of Hom-Kularb-Dang crude rice bran gave an extract that contains procyanidinin. The crude extract was able to scavenge DPPH radicals and was 
non-cytotoxic to skin human fibroblast. The extract exposed to UVB-irradiated human fibroblast significantly prevented MMP-1 secretion. While promoting enhanced levels of extracellular type I procollagen. Our findings suggest that HKD extract has the potential to be used as an agent for skin photodamage prevention.

\section{ACKNOWLEDGEMENTS}

We would like to thank the Research and Researcher for Industry (RRI) and S \& J International Enterprises Public Company Limited for the research grant and financial support.

\section{REFERENCES}

Ahn, B. N., Kim, J. A., Himaya, S. W. A., Bak, S. S., Kong, C. S., and Kim S. K. 2012. Chitooligosaccharides attenuate UVB-induced damages in human dermal fibroblasts. Naunyn-Schmiedeberg's Archives of Pharmacology. 385: 95-102. https://doi.org/10.1007/s00210-011-0684-0

Aguilar-Garcia, C., Gavino, G., Baragaño-Mosqueda, M., Hevia, P., and Gavino V. 2007. Correlation of tocopherol, tocotrienol, $\gamma$-oryzanol, and total polyphenol content in rice bran with different antioxidant capacity assays. Food Chemistry. 102: 1228-1232. https://doi.org/10.1016/ j.foodchem.2006.07.012

Bagchi, D., Garg, A., Krohn, R.L., Bagchi, M., Tran, M.X., and Stohs, S.J. 1997. Oxygen free radical scavenging abilities of vitamins $\mathrm{C}$ and $\mathrm{E}$, and a grape seed proanthocyanidin extract in vitro. Research Communications in Molecular Pathology and Pharmacology. 95: 179-189.

Bhupathiraju, S.N., and Tucker, K.L. 2011. Coronary heart disease prevention: nutrients, foods, and dietary patterns. Clinica Chimica Acta. 412: 1493514. https://doi.org/ 10.1016/j.cca.2011.04.038

Brennan, M., Bhatti, H., Nerusu, K.C., Bhaqavathula, N., Kang, S., Fisher, G.J., Varani, J., and Voorhees, J.J. 2003. Matrix metalloproteinase-1 is the major collagenolytic enzyme responsible for collagen damage in UV-irradiated human skin. Photochemistry and Photobiology. 78: 43-48. https://doi.org/ 10.1562/0031-8655(2003)078<0043:mmitmc $>2.0 . c 0 ; 2$

Butsat, S., and Siriamornpun, S. 2010. Antioxidant capacities and phenolic compounds of the husk, bran and endosperm of Thai rice. Food Chemistry. 119: 606-613. https://doi.org/10.1016/j.foodchem.2009.07.001

Chen, Y.J., Chen, Y.Y., Wu, C.T., Yu, C.C., and Liao, H.F. 2010. Prolamin, a rice protein, augments anti leukaemia immune response. Journal of Cereal Science. 51: 189-197. https://doi.org/10.1016/j.jcs.2009.11.011 
Chiang, H.M., Chen, H.C., Lin, T.J., Shin, I.C., and Wen, K.C. 2012. Michelia alba extract attenuates UVB- induced expression of matrix metalloproteinases via MAP kinase pathway in human dermal fibroblasts. Food and Chemical Toxicology. 50: 4260-4269. https://doi.org/10.1016/ j.fct.2012.08.018

Choi, C.P., Kim, Y.I., Lee, J.W. and Lee, M.H. 2007. The effect of narrowband ultraviolet $\mathrm{B}$ on the expression of matrix metalloproteinase-1, transforming growth factor-beta1 and type I collagen in human skin fibroblasts. Clinical and Experimental Dermatology. 32: 180-185. https://doi.org/10.1111/j.13 65-2230.2006.02309.x

Chotimarkorn, C., Benjakul, S., and Silalai, N. 2008. Antioxidant components and properties of five long-grained rice bran extracts from commercial available cultivars in Thailand. Food Chemistry. 111: 636-641. https://doi.org/10.1016/j.foodchem.2008.04.031

Chulasiri, M., Wanaswas, P., Sriaum, D., Nakamat, S., Wongkrajang, Y., Kongsaktrakoon, B., Phomchirasilp, S., and Leelarungrayub, D. 2011. Utilizing hydroglycolic extract from myrobalan fruits to counteract reactive oxygen species. International Journal of Cosmetic Science. 33: 371-376. https://doi.org/10.1111/j.1468-2494.2011.00642.x

Déziel, B.A., Patel, K., Neto, C., Gottschall-Pass, K., and Hurta, R.A. 2010. Proanthocyanidins from the American Cranberry (Vaccinium macrocarpon) inhibit matrix metalloproteinase- 2 and matrix metalloproteinase-9 activity in human prostate cancer cells via alterations in multiple cellular signalling pathways. Journal of Cellular Biochemistry. 111: 742-754. https://doi.org/10.1002/jcb.22761

Dong, K.K., Damaghi, N., Picart, S.D., Markova, N.G., Obayashi, K., Okano, Y., Masaki, H., Grether-Beck, S., Krutmann, J., Smiles, K.A., et al. 2008. UV-induced DNA damage initiates release of MMP- 1 in human skin. Experimental Dermatology. 17: 1037-1044. https://doi.org/10.1111/ j.1600- 0625.2008.00747.x

Duangjai, A., Suphrom, N., Wungrath, J., Ontawong, A., Nuengchamnong, N., and Yosboonruang, A. 2016. Comparison of antioxidant, antimicrobial activities and chemical profiles of three coffee (Coffea arabica L.) pulp aqueous extracts. Integrative Medicine Research. 5: 324-331. https://doi.org/10.1016/j.imr.2016.09.001

Fligiel, S., Varani, J., Datta, S., Kang, S., Fisher, G., and Voorhees, J. 2003. Collagen degradation in aged/photodamaged skin in vivo and after exposure to matrix metalloproteinase- 1 in vitro. Journal of Investigative Dermatology. 120: 842-848. https://doi.org/10.1046/j.1523-1747.2003. 12148.x

Itsarasook, K., Ingkaninan, K., and Viyoch, J. 2014. Artocarpin-enriched extract reverses collagen metabolism in UV-exposed fibroblasts. Biologia. 69: 943-951. https://doi.org/10.2478/s11756-014-0394-4 
Gu, L., Kelm, M.A., Hammerstone, J.F., Zhang, Z., Beecher, G., Holden, J., Haytowitz, D., and Prior, R.L. 2003. Liquid chromathographic/ electrospray ionization mass spectrometric studies of proanthocyanidins in foods. Journal of Mass Spectrometry. 38:1272-1280. https://doi.org/ $10.1002 / \mathrm{jms} .541$

Gunaratne, A., Wu, K., Li, D., Bentota, A., Corke, H., and Cai, Y.Z. 2013. Antroxidant activity and nutritional quality of traditional red-grained rice varieties containing proanthocyanidins. Food Chemistry.138: 1153-1161. https://doi.org/10.1016/j.foodchem.2012.11.129

Huang, Y.P., and Lai, H.M. 2016 Bioactive compounds and antioxidative activity of colored rice bran. Journal of Food and Drug Analysis. 24(3): 564-574. https://doi.org/10.1016/j.fda.2016.01.004

Inpanya, P., Faikrua, A., Ounaroon, A., Sittichokechaiwut, A., and Viyoch, J. 2012. Effects of the blended fibroin/aloe gel film on wound healing in streptozotocin-induced diabetic rats. Biomedical Materials. 7(3): 035008. https://doi.org/10.1088/1748-6041/7/3/035008

Kannan, A., Hettiarachchy, N. S., Lay, J. O., and Liyanage, R. 2010. Human cancer cell proliferation inhibition by a pentapeptide isolated and characterized from rice bran. Peptides. 31: 1629-1634. https://doi.org/ 10.1016/j.peptides.2010.05.018

Limtrakul, P., Yodkeeree, S., Pitchakarn, P., and Punfa, W. 2016. Antiinflammatory effects of proanthocyanidin- rich red rice extract via suppression of MAPK, AP- 1 and NF- $\kappa$ B pathways in Raw 264. 7 macrophages. Nutrition Research and Practice. 10: 251-258. https://doi. org/10.4162/nrp.2016.10.3.251

Leardkamolkarn, V., Thongthep, W., Suttiarporn, P., Kongkachuichai, P., Wongpornchai, S., and Wanavijitr, A. 2010. Chemopreventive properties of the bran extracted from newly-developed Thai rice: the riceberry. Food Chemistry. 125: 978-985. https://doi.org/ 10.1016/j.foodchem.2010.09. 093

Lu, Y., and Foo, L.Y. 1999. The polyphenol constituents of grape pomace. Food Chemistry. 65: 1-8. https://doi.org/10.1016/S0308-8146(98)00245-3

Lv, Q., Luo, F., Zhao, X., Liu, Y., Hu, G., Sun, C., Li, X., and Chen, K. 2015. Identification of Proanthocyanidins from Litchi (Litchi chinensis Sonn.) Pulp by LC-ESI-Q-TOF-MS and Their Antioxidant Activity. Plos One. https://doi.org/10.1371/journal.pone.0120480

Park, J.E., Pyun, H.B., Woo, S. W., Jeong, J.H., and Hwang, J. K. 2014. The protective effect of Kaempferia parviflora extract on UVB-induced skin photoaging in hairless mice. Photodermatology, Photoimmunology \& Photomedicine. 30: 237-245. https://doi.org/10.1111/phpp.12097 
Phetdee, K., Rakchai, R., Rattanamanee, K., Teaktong, T., and Viyoch, J. 2014. Preventive effects of tamarind seed coat extract on UVA- induced alterations in human skin fibroblasts. Journal of Cosmetic Science. 65: 1124.

Quan, T., He, T., Kang, S., Voorhees, J.J., and Fisher, G.J. 2004. Solar ultraviolet irradiation reduces collagen in photoaged human skin by blocking transforming growth factor beta type 1 receptor/Smad signaling. American Journal of Pathology. 165: 741-751. https://doi.org/10.1016/s0002-9440 (10)63337-8

Quan, T., Qin, Z., Xia, W., Shao, Y., Voorhees, J.J., and Fisher, G.J.. 2009. Matrix-degrading Metalloproteinases in Photoaging. Journal of Investigative Dermatology Symposium Proceedings. 14: 20-24. https://doi. org/10.1038/jidsymp.2009.8

Ricardo da Silva, J.M., Darmon, N., Fernandez, Y., and Mitjavila, S. 1991. Oxygen free radical scavenger capacity in aqueous models of different procyanidins from grape seeds. Journal of Agriculture and Food Chemistry. 39: 1549-1552. https://doi.org/10.1021/jf00009a002

Samad, N. 2015. Rice bran oil prevent neuroleptic-induced extrapyramidal symtoms in rats: possible antioxidant mechanisms. Journal of Food and Drud Analysis. 23:370-375. https://doi.org/10.1016/j.fda.2014.10.012

Sanchez-Moreno, C., Larrauri, J.A., and Saura-Clixto, F. 1998. A procedure to measure the antiradical efficiency of polyphenols. Journal of the Science of Food and Agriculture. 79:270-276. https://doi.org/10.1002/(SICI)10970010(199802)76:2<270::AID-

Torel, J., Cillard, J., and Cillard, P. 1986. Antioxidant activity of flavonoids and reactivity with peroxy radical. Phytochemistry. 25: 383-385. https://doi. org/10.1016/S0031-9422(00)85485-0

Varani, J., Perone, P., Fligiel, S.E., Fisher, G.J., and Voorhees, J.J. 2002. Inhibition of type I procollagen production in photodamage: correlation between presence of high molecular weight collagen fragments and reduced procollagen synthesis. Journal of Investigative Dermatology. 119: 122-129. https://doi.org/10.1046/j.1523-1747.2002.01810.x

Viyoch, J., Mahingsa, K., and Ingkaninan, K. 2012. Effects of Thai Musa species on prevention of UVB-induced skin damage in mice. Food and Chemical Toxicology. 50: 4292-4301. https://doi.org/10.1016/j.fct.2012.08.060

Wang, F., Garza, L.A., Kang, S., Varani, J., Orringer, J.S., Fisher, G.J., and Voorhees, J.J. 2007. In vivo stimulation of de novo collagen production caused by cross-linked hyaluronic acid dermal filler injections in photodamaged human skin. Archives of dermatologica. 143: 155-163. https://doi.org/10.1001/archderm.143.2.155 
Wen, K. C., Fan, P.C., Tsai, S. Y., Shih, I.C., and Chiang, H. M. 2012. Ixora parviflora protects against UVB-induced photoaging by inhibiting the expression of MMPs, MAP kinases, and COX-2 and by promoting type I procollagen synthesis. Evidence-Based Complementary and Alternative Medicine. 2012: 417346. https://doi.org/10.1155/2012/417346

Wittenauer, J., Mäckle, S., Sußmann, D., Schweiggert-Weisz, U., and Carle, R. 2015. Inhibitory effects of polyphenols from grape pomace extract on collagenase and elastase activity. Fitoterapia. 101: 179-187. https://doi.org/ 10.1016/j.fitote.2015.01.005

Yakaew, S 2013. Potential of Thai herbal extracts for application as skin anti-aging [master's thesis]. Phitsanulok: Naresuan University.

Yakaew, S., Itsarasook, K., Ngoenkam, J., Jessadayannamaetha, A., Viyoch, J., and Ungsurungsie, M. 2016. Ethanol extract of Terminalia chebula fruit protects against UVB-induced skin damage. Pharmaceutical Biology. 54: 2701-2707. https://doi.org/ 10.1080/13880209.2016.1179768

Zhao M., Yang B., Wang J., Li B., and Jiang Y. 2006. Identification of the major flavonoids from pericarp tissues of lychee fruit in relation to their anti- oxidation activities. Food Chemistry. 98: 539-544. https://doi.org/ 10.1016/j.jff.2013.11.022 